\title{
Métodos de Irrigação na Produtividade da Cana-de-Açúcar
}

Methods of Irrigation in the Productivity of Sugarcane

Métodos de Riego en la Productividad de la Caña de Azúcar

Maria Isabela de Souza dos Santos

Bolsista PIBIC Júnior, UNESP, Brasil.

isabeladonato5@gmail.com

\section{Ana Cláudia Marassá Roza Boso \\ Mestranda, UNESP, Brasil \\ Claudia_boso@hotmail.com}

\section{Camila Pires Cremasco Gabriel \\ Professor Mestre, UEMS, Brasil. camila@tupa.unesp.br}




\section{RESUMO}

A irrigação da cana de açúcar cresce a cada ano em nosso território, necessitando o desenvolvimento de estudos que auxiliam no modelo de cultivo da cultura. Esses estudos permitem a melhoria da quantidade e qualidade da produtividade da cultivação. No entanto, a falta hídrica em algumas regiões possibilita o aumento de perdas da cultura durante a sua produção, necessitando assim a implementação dos métodos de irrigação na lavoura.

Os métodos que mais se destacam na produtividade da cana-de-açúcar são a irrigação localizada e irrigação por aspersão. A irrigação localizada é um método muito eficiente por ter a vantagem da água cair diretamente na raiz da planta, fazendo com que a mesma cresça mais rápido com uma qualidade e quantidade maior. A irrigação por aspersão é um método conhecido como uma chuva artificial, onde a água é aplicada por aspersores, sob pressão, no solo e na planta. Observando a importância dos métodos para irrigação, o objetivo do presente trabalho está em analisar e verificar o método de irrigação que se destaca na produtividade da cana-de-açúcar nas usinas da região de Tupã/SP.

PALAVRAS-CHAVE: Água. Cultura. Crescimento.

\section{ABSTRACT}

Irrigation of sugarcane grows every year in our territory, necessitating the development of studies that aid in the cultivation model of the crop. These studies allow the improvement of the quantity and quality of cultivation productivity. However, the lack of water in some regions makes it possible to increase crop losses during its production, thus requiring the implementation of irrigation methods in the crop.

The methods that stand out most in sugarcane productivity are localized irrigation and sprinkler irrigation. Localized irrigation is a very efficient method because it has the advantage of water falling directly into the root of the plant, causing it to grow faster with a higher quality and quantity. Sprinkler irrigation is a method known as artificial rainfall where water is applied by sprinklers under pressure to the soil and plant. Observing the importance of the methods for irrigation, the objective of this work is to analyze and verify the irrigation method that stands out in the sugarcane productivity in the Tupã / SP.

KEYWORDS: Water. Culture. Growth.

\section{RESUMEN}

La irrigación de la caña de azúcar crece cada año en nuestro territorio, necesitando el desarrollo de estudios que auxilian en el modelo de cultivo de la cultura. Estos estudios permiten la mejora de la cantidad y calidad de la productividad de la cultivación. Sin embargo, la falta hídrica en algunas regiones posibilita el aumento de pérdidas de la cultura durante su producción, necesitando así la implementación de los métodos de riego en la labranza.

Los métodos que más se destacan en la productividad de la caña de azúcar son la irrigación localizada e irrigación por aspersión. La irrigación localizada es un método muy eficiente por tener la ventaja del agua caer directamente en la raíz de la planta, haciendo que la misma crezca más rápido con una calidad y cantidad mayor. La irrigación por aspersión es un método conocido como una lluvia artificial, donde el agua es aplicada por aspersores, bajo presión, en el suelo y en la planta. Al observar la importancia de los métodos para irrigación, el objetivo del presente trabajo está en analizar y verificar el método de riego que se destaca en la productividad de la caña de azúcar en las usinas de la región de Tupã / SP.

PALABRAS CLAVE: Agua. Cultura. Crecimiento. 


\section{INTRODUÇÃO}

A utilização de métodos de irrigação vem obtendo grande espaço na agricultura. Seus benefícios se concentra na aplicação de recursos hídricos quando necessário e na complementação de nutriente.

Atualmente é empregado três tipos de métodos de irrigação, o superficial, o aspersão e o gotejamento. Ambos eficientes de acordo com a topografia do local e as características da cultura a ser produzida.

Segundo Bernardo, Soares e Mantovani (2006, p.625), a irrigação por superfície: consiste na aplicação da água em todos os sistemas de plantio. Seu objetivo está em movimentar a água por gravidade diretamente sobre o solo. Ainda segundo os autores, esse sistema de irrigação é recomendado somente para o solo de textura médio-argilosa e com a topografia plana. É um método de baixo custo de energia e operacional e com utilização de equipamentos simples.

A irrigação por aspersão é um método semelhante ao processo da chuva, sendo conhecido como chuva artificial. Esse sistema tem o intuito de aspergir a água sob a superfície do terreno. Sua vantagem se concentra na sua aplicação em locais com textura mais grossa (MANTOVANI; BERNARDO; PALARETTI, 2006, p. 318). O método de irrigação por aspersão é subdividido em irrigação por aspersão convencional, irrigação por pivô central, irrigação por deslocamento linear e irrigação autopropelido.

O método irrigação localizada é o mais eficiente em relação aos demais. Seu objetivo está em aplicar diretamente a água na raiz da planta, obtendo bons resultados relacionados com a produtividade da cultura (DALRI; CRUZ, p. 30). A exigência desse sistema está na grande intensidade de aplicação com redução de danos ao meio ambiente.

Uma cultura que não necessita de aplicação constante de água, mas essencial em períodos de seca é a cana-de-açúcar. Com a comercialização em grande escala de seus derivados, torna-se essencial a utilização de métodos e irrigação em seu desenvolvimento, principalmente em períodos de estiagem.

De acordo com GAVA et al. (2008, p. 752), a cana-de-açúcar se adapta ao método de irrigação por gotejamento subsuperficial. Sua produção se eleva, pois a água é aplicada diretamente na raiz da planta, obtendo assim um menor índice de desperdiço dos recursos hídricos.

Pensando no crescimento e expansão territorial dessa cultura, o presente estudo tem como objetivo analisar e avaliar, de acordo com os métodos de irrigação utilizados, a produtividade da cana-de-açúcar localizadas na região de Tupã no estado de São Paulo, por meio de pesquisa e questionários nas usinas da região.

\section{METODOLOGIA}

O presente trabalho foi desenvolvido por meio de análises de artigos, teses, pesquisas literárias e questionários realizados em algumas usinas da região de Tupã/SP, que trabalham com a produção da cana de açúcar. 
Entre vários métodos de irrigação existentes, o cultivo dessa planta possibilita a utilização dos seguintes métodos de irrigação: localizada, aspersão e superficial.

Em seguida foi realizado uma comparação das respostas obtidas do questionário aplicado, com os resultados encontrados na literatura.

\subsection{MÉTODO DE IRRIGAÇÃO LOCALIZADA}

No método de irrigação localizada a água é aplicada diretamente na raiz da planta, necessitando de uma concentração de tubulações maior em relação aos demais métodos de irrigação. Esse método se destaca pela eficiência do uso de água, economia de mão-de-obra, diminuição da perdas por evaporação e maior produtividade da cultura (BERNARDO; SOARES; MANTOVANI, 2006, p.625). Em suas desvantagens, pode-se destacar elevação de custo de implementação do sistema e entupimento das tubulações (Figura 1).

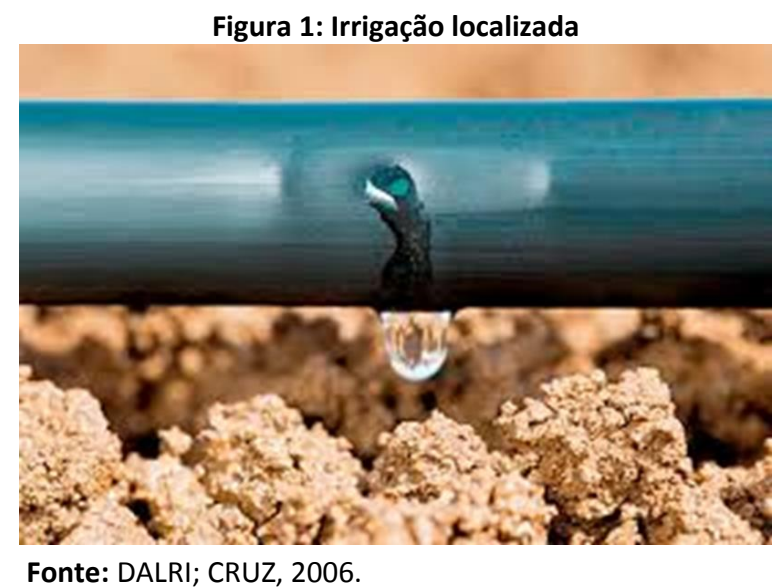

\subsection{MÉTODO DE IRRIGAÇÃO POR ASPERSÃO}

O método de irrigação por aspersão é muito comparado a uma chuva artificial, onde consiste em aspergir a água com a ajuda de motobombas, aspersores e tubulações. Suas vantagens se concentrar em atingir grande quantidade de área irrigada e utilização em terrenos não sistematizados (MANTOVANI; BERNARDO; PALARETTI, 2006, p. 318). Suas desvantagens estão na proliferação de doenças geradas pela umidade nas folhas, perda de água por evaporação e movimentação do vento.

Ainda segundo o autor, no modo convencional, os aspersores podem ser portáteis, semifixos e fixos, necessitando de mão-de-obra para a movimentação dos equipamentos (Figura 2). Esse sistema consiste em formato de malha, onde as tubulações são enterradas. 


\section{da Alta Paulista}

Figura 2: Modo convencional de aspersores

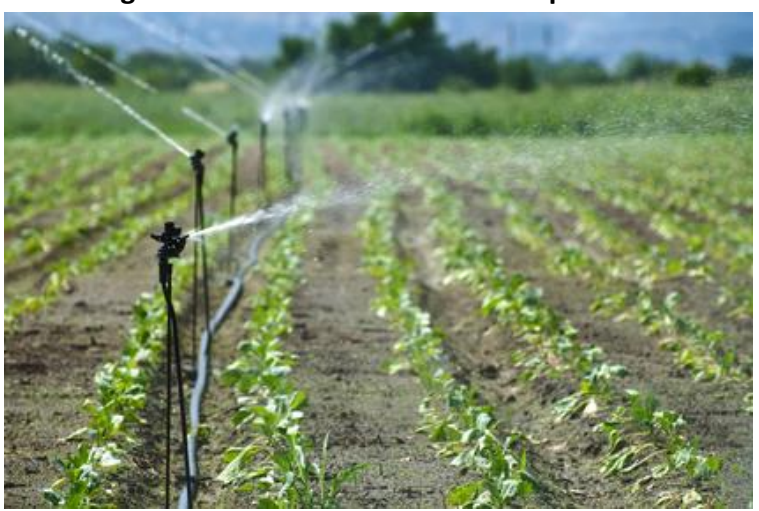

Fonte: DALRI; CRUZ, 2006)

O sistema autopropelido é composto por um único canhão que se movimenta ao longo área plantada (Figura 3). Esse sistema não necessita de mão de obra, pois seu sistema é gerado por meio de energia hidráulica. Suas desvantagens se concentra no grande consumo de energia e grandes perdas pelo vento (BERNARDO; SOARES; MANTOVANI, 2006, p.625).

Figura 3: Sistema autopropelido

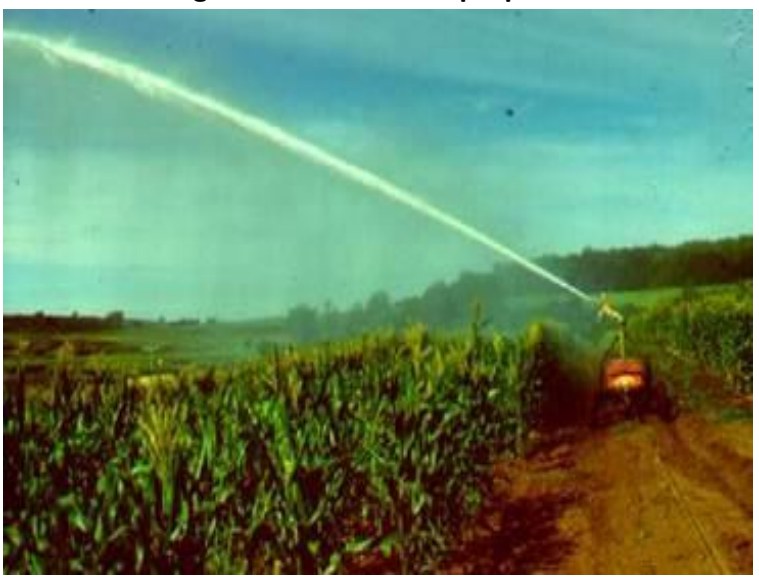

Fonte: BERNARDO, 2006.

Pouco utilizado no cultivo da cana-de-açúcar, o sistema de pivô central é movido por energia a diesel ou elétrica (Figura 4). Esse sistema constitui-se de uma linha lateral que se movimenta em círculo ao redor de um pivô central. No entanto há limitações com a topografia do local a ser instalado (DALRI; CRUZ, p. 33). 


\section{da Alta Paulista}

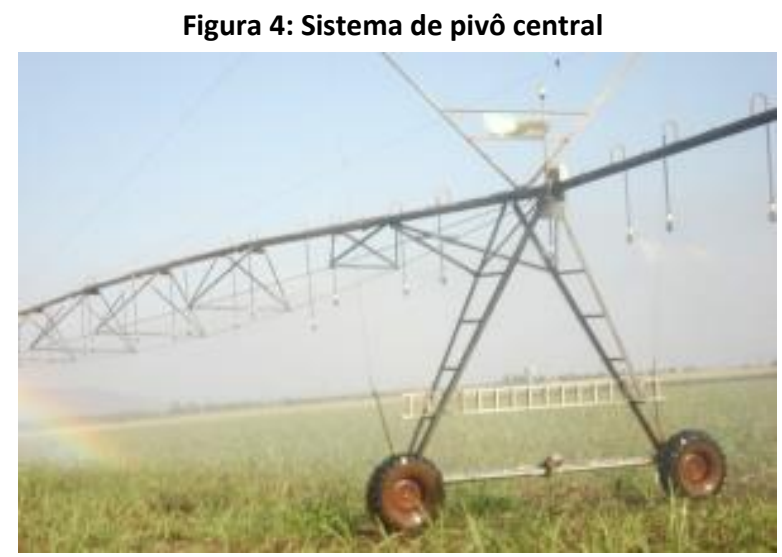

Fonte: MANTOVANI; BERNARDO; PALARETT, 2006.

\subsection{MÉTODO DE IRRIGAÇÃO POR SUPERFÍCIE}

O método de irrigação por superfície consiste na movimentação da água sobre o solo, até as raízes da planta, com a força da gravidade. Com baixo custo operacional e equipamentos simples, o sistema se torna vantajoso dependendo da cultura a ser utilizada (MANTOVANI; BERNARDO; PALARETT, 2006, P.320).

Segundo os autores, o sistema de irrigação por superfície se divide em três sistemas: irrigação por sulco, irrigação por faixa e irrigação por inundação. Por sulco a água é filtrada e se movimenta de forma lateral e vertical, umedecendo o solo. Por faixa, a água é aplicada sob a terra com uma certa declividade, sendo utilizada para culturas com cobertura $100 \%$ da superfície do solo (DALRI; CRUZ, p. 33). Por inundação, a água é mantida sob o solo durante todo o processo de cultivo.

Figura 5: Irrigação por superfície

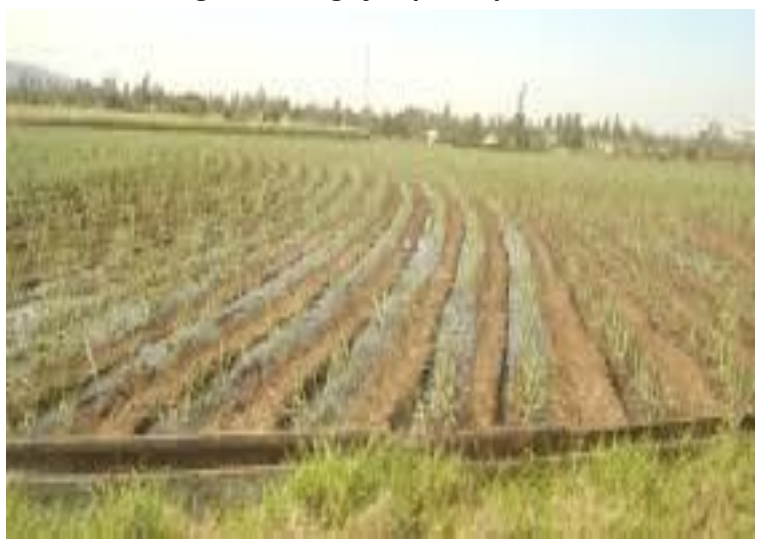

Fonte: BERNARDO, 2006. 


\subsection{QUESTIONÁRIO DE INVESTIGAÇÃO}

O questionário aplicado nas fazendas da região de Tupã/SP, sobre a produtividade da cana-deaçúcar relacionada com os métodos de irrigação, é composto por 8 perguntas. As usinas à serem analisadas foram: Usina Clealco, que consiste em três localidades: 1 . Fazenda Pouso Alegre, Zona Rural em Queiroz/SP; 2. Rod. SP 419 - Raul Forchero Casasco, Km 6 em Penápolis/SP; 3. Rod. SP 425 Entronc. Rod. SP 463, km 01 - Industrial em Clementina/SP; Usina Califórnia, localizada na Fazenda São Francisco, Bairro Monte Alegre- Parapuã/SP; e na Fazenda Taperão, onde a sua localização é na cidade de Brotas/SP.

Tabela 1. Questionário

\section{Perguntas}

1 - Qual métodos de irrigação é utilizado no cultivo da cana-de-açúcar? 2 - Por que esse método é utilizado?

3 - Como esse método auxilia na produtividade da cana-de-açúcar? 4-A produtividade é a maior ou menor com o método de irrigação utilizado?

5 - Vocês testaram outros métodos de irrigação para verificar a produtividade da cana de açúcar?

6 - Qual espécie de cana-de-açúcar que vocês utilizam para plantação? Por que?

7- É utilizado fertirrigação no processo de irrigação?

8- Qual método é melhor para produtividade da cana?

Fonte: Autor.

O questionário teve como objetivo verificar quais métodos de irrigação são utilizados nas usinas, observando a produtividade e qualidade da cultura.

\section{RESULTADOS}

De acordo com os questionários realizados nas fazendas, observou-se que o método de irrigação mais utilizado nas usinas Clealco e Califórnia é por aspersor na forma canhão. Esse sistema é utilizado apenas para fertirrigação, quando necessário a introdução de potássio. A substância utilizada para fertirrigação é a vinhaça, onde ela representa a sobra de resíduos pastosos da destilação do caldo da cana-de-açúcar fermentada para aquisição do etanol.

A utilização desse método está relacionado com o seu custo operacional, com a resistência do equipamento, a mobilidade do sistema e a necessidade de poucos equipamentos trafegando sobre a louva. Sua utilização é encontrada em fazendas de pequeno porte, sendo a sua aplicação em $100 \%$ de toda a área irrigada.

De acordo com a usina Clealco, o método de irrigação por aspersor aumenta produtividade em 10 tonelada por hectare, quando utilizado em junção da fertirrigação por vinhaça. É notável que a produtividade varia de acordo com as condições climática da região.

De acordo com a Usina Califórnia, outros métodos foram testados na cultura da cana-deaçúcar. No entanto a utilização dos métodos de irrigação por gotejamento e superficial não 
foram satisfatórios para a estrutura e poder aquisitivo da fazenda, sendo assim inviável a instalação desses métodos na fazenda.

Outro fator importante para a produtividade da cana-de-açúcar descrita pelas fazenda é a espécie a ser utilizada para o cultivo. O gênero de classificação da planta é o Saccharum, sendo subdivida em diversas espécies. A espécie mais utilizada pelas fazendas é o Officianarum, porém existe outras espécies modificadas geneticamente em laboratório que são utilizadas para obter resistência as pragas e produção de qualidade com maior produtividade.

De acordo com a Usina Clealco, algumas fazendas trabalham com pelo menos dez variedades diferentes da cultura para obtenção da produtividade. Observou-se que a utilização da variedade depende das condições climática da região, bem como o tipo de solo e a época de maturação da espécie. Em contra partida, a fazenda Taperão utiliza em seus 420 hectares de cultiva de cana-de-açúcar, o método de irrigação por gotejamento localizado subterrâneo. A utilização desse método está relacionado com a eficiência do sistema, das condições climáticas da região de Brotas e do poder de aquisição da fazenda. Esse sistema tem um custo alto em sua instalação, mas compensável pelo aumento da produtividade da cultura.

O aumento da produtividade da cultura, pelo método de irrigação por gotejamento subterrâneo, na fazenda Taperão, vária entre 10 a 15 toneladas por hectares. Esse aumento de produtividade da cultura está relacionado com a utilização da fertirrigação no sistema de irrigação. Ao contrário das fazendas mencionadas acima, a fazenda Taperão utiliza um sistema de fertirrigação diferente da vinhaça. A solução utilizada para fertirrigação é composta por nitrogênio, potássio e complementação. O proprietário evita utilizar adubos fosfatados, devido o tipo de solo encontrado na propriedade. A utilização do fosfato ocorre apenas no sulco de plantio, e quando utilizado, o melhor é o MAP purificado.

Conforme os estudos realizados por NETO et al. (2006, p. 287), a produtividade da cultura de acordo coma soca e a ressoca foi de $43.5 \%$ e $67.2 \%$ respectivamente sobre a testemunha, que não foi irrigada. Essa produtividade foi resultado da utilização da fertirrigação no sistema de gotejamento. No entanto foram utilizado substâncias diferente da vinhaça nesse sistema.

Os estudos realizados por GAVA et al. (2008, p. 754), demostraram que houve aumento na produtividade da cana-de-açúcar por meio da utilização da fertirrigação em sistema de gotejamento subterrâneo. A produtividade dos colmo da cana-de-açúcar obteve um aumento de $24 \%$ e a produção da cultura um aumentou de $23 \%$. O estudo utilizou a uréia e o cloreto de potássio para fertirrigação da cultura.

\section{CONCLUSÃO}

A partir dos estudos direcionados à produtividade da cana-de-açúcar, conclui-se que a utilização dos métodos de irrigação por gotejamento e superficial com canhão, aumentam a produtividade e qualidade da cultura.

A utilização desses dois métodos varia de acordo com as características climáticas da região, do tipo de solo a ser utilizado, do poder aquisitivo do produtor e da variedade da cultura. 
As culturas modificadas e desenvolvidas em laboratório obterem melhores resultados na qualidade e quantidade de produção.

Com a implementação da fertirrigação ao sistema de irrigação, obtém-se respostas significativas da produtividade da cultura.

Entre os sistemas de irrigação analisados, o gotejamento subterrâneo demostrou maior eficiência em relação ao sistema autopropelido (aspersor por canhão), pois houve grande eficiência com aplicação de fertilizantes, com poucas perdas de eficiência.

\section{AGRADECIMENTO}

Agradeço à Associação Amigos da Natureza da Alta Paulista(ANAP), em associação coma o Simpósio Brasileiro sobre Governança e Desenvolvimento Sustentável, pela oportunidade de espaço na realização e publicação desse trabalho.

Agradecimento à instituição CNPQ pela cessão de uma bolsa PIBIC, o que permitindo a realização desse artigo.

\section{REFERÊNCIA}

BERNARDO, Salassier; SOARES, Antônio Alves; MANTOVANI, Everardo Chartuni. Manual de irrigação. 8. ed. Viçosa: UFV, 2006. $625 \mathrm{p}$.

BERNARDO, Salassier. Manejo da irrigação na cana-de-açúcar. Alcoolbrás, São Paulo, n. 106, 2006. 72-80 p.

DALRI, Alexandre Barcellos.; CRUZ, Raimundo Leite. Efeito da frequência de irrigação subsuperficial por gotejamento no desenvolvimento da cana-de-açúcar (Saccharum spp.). Irriga, Botucatu, v. 7, n.1, 2002. 29-34 p.

FARIAS, Carlos et al. Índices de crescimento da cana-de-açúcar irrigada e de sequeiro no Estado da Paraíba. R. Bras. Eng. Agríc. Ambiental, v.12, n.4, 2008. 356-362 p.

GAVA, José Glauber et al. Produtividade e atributos tecnológicos de três cultivares de cana-de-açúcar irrigadas por gotejamento subsuperficial. In: CONGRESSO NACIONAL DA STAB, 9, 2008. Anais. Maceió: STAB, 2008. 751-755 p.

JUNIOR, Anderson Soares de Andrade et al. Irrigação e fertirrigação na produção de cana-de-açúcar. Disponível em: < http://www.grupocultivar.com.br/artigos/irrigacao-e-fertirrigacao-na-producao-de-cana-de-acucar> . Acesso em: 12 fev. 2016.

MANTOVANI, Everardo Chartuni; BERNARDO, Salassier.; PALARETTI, Luiz Fabiano. Irrigação: Princípios e Métodos. Viçosa: ED. UFV, 2006. 318 p.

MATIOLI, Clebio Santo et al. Análise de decisão sobre a viabilidade da irrigação suplementar de cana-de-açúcar colhida no mês de julho na região de Ribeirão Preto-SP. In: CONGRESSO BRASILEIRO DE ENGENHARIA AGRÍCOLA, 25, CONGRESSO LATINOAMERICANDO DE INGENIERIA AGRÍCOLA, 2, Bauru, 1996. Anais... Bauru, 1996.

NETO, José Dantas et al. Resposta da cana-de-açúcar, primeira soca, a níveis de irrigação e adubação de cobertura. R. Bras. Eng. Agríc. Ambiental, v.10, n.2, 2006. 283-288 p.

PAZ, Vital Pedro da Silva et al. Recursos hídricos, agricultura irrigada e meio ambiente. R. Bras. Eng. Agríc. Ambiental, Campina Grande, v.4, n.3, 2000. 465-473 p. 